\title{
A Study on Prevalence and Clinico-Mycological Profile of Superficial Fungal Infections in a Tertiary Care Hospital
}

\author{
C.L. Vasudha ${ }^{1}$, B. Anuradha ${ }^{2}$ and Meer Muzaffar Ali Faizan ${ }^{3}$ \\ ${ }^{1}$ Department of Microbiology, Mamata Medical College, Rotary nagar, Khammam, \\ Telangana - 507002, India \\ ${ }^{2}$ Dept of Microbiology, Mamata Medical College, Khammam, Telangana, India \\ ${ }^{3}$ Intern, Mamata Medical College, Khammam, Telangana, India
}

*Corresponding author

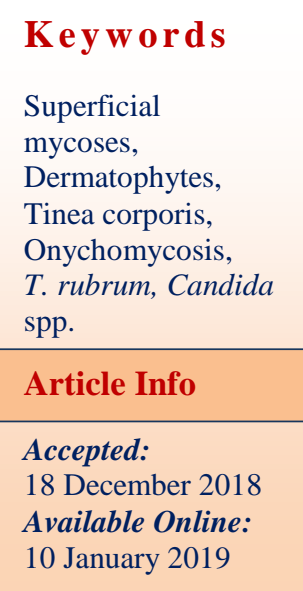

\section{Introduction}

Fungal infections are worldwide in distribution of which superficial infections are the most common human infections (Brown et al., 2012). These are rarely life threatening but they have their own negative effects on the patient's emotional, social and occupational
The incidence of superficial mycoses has increased recently due to frequent usage of antibiotics and various immunosuppressive conditions. In the background of immunosuppression, detection of these agents becomes necessary for effective management and prevention of further invasions. The objective of the study was to determine the prevalence and causative agents of superficial mycoses in order to provide early and efficient treatment. A cross-sectional study was conducted for 3 months (JuneAugust 2015) on patients with suspected superficial mycoses attending our Dermatology OPD. Skin, hair and nail samples were collected and transported aseptically to Microbiology laboratory for further processing. Out of the 394 cases that attended the dermatology OPD, 48 clinically suspected cases of superficial mycoses were studied. Prevalence of superficial mycoses was $10.4 \%$. 41 cases showed positive culture, while only 37 cases were $\mathrm{KOH}$ positive. T. rubrum was the most common dermatophyte $(48.27 \%)$ and the commonest causative agent $(34.14 \%)$ while Candida spp were the most common non-dermatophyte $(50 \%)$ and 3rd most common etiological agent (12.20\%) isolated. We concluded that along with dermatophytes, dermatomycotic fungi are also emerging as an important cause of superficial mycoses. Though culture was found to be more sensitive than $\mathrm{KOH}$ mount, both techniques are important tools of diagnosis. 
species and other non-dermatophytic moulds such as Aspergillus spp, Fusarium sppand Acremonium species. They have affinity for tissues that are keratin rich like skin, hair and nails, and thus they produce inflammatory response associated with clinical signs and symptoms such as itching etc, along with cosmetic defects. The three genera of dermatophytes that are recognised are Epidermophyton, Microsporum and Trichophyton (Grover and Roy, 2003)

Over the last decades, an increasing number of non - dermatophyte filamentous fungi have been recognized as agents of skin and nail infections in humans, producing lesions clinically similar to those caused by dermatophytes (Patel et al., 2010).

Recently there has been an increase in the incidence of fungal infections. This increase may be a result of frequent usage of antibiotics, immunosuppressive drugs and various conditions like organtransplantations, lymphomas, leukemia and Human Immunodeficiency Virus (HIV) infections (Petmy et al., 2004).

Previously these infections were considered as mere cosmetic problems but in recent years these have gained importance as major public health problems. This is because affected patients experience embarrassment in social and work situations, where they feel unclean, unwilling to allow their hands or feet to be seen. Patients may fear that they will transmit their infection to family members, friends, or co-workers, fears that can lead to diminished self-esteem and the avoidance of close relationship. In fact, many patients with fungal nail infections experience serious physical, psychosocial, and occupational effects as a result of this disease.

A correct diagnosis is important to initiate appropriate treatment and also essential for epidemiological purposes. In the background of immunosuppression, detection of these agents becomes mandatory for the effective management of mycoses to prevent further invasions (Kannan et al., 2006).

The present study was conducted to know the prevalence and possible etiological agents of superficial fungal infections in our area, in order to provide early and appropriate treatment to reduce the social burden.

The objective of the study is to determine the prevalence and causative agents of superficial fungal infections in order to provide early and efficient treatment and reduce the morbidity.

\section{Materials and Methods}

This is a cross-sectional study conducted for a period of 3 months (June- August 2015) and included patients of various age groups with suspected superficial mycoses attending the outpatient department (OPD) of Dermatology of our hospital. The institutional ethical committee clearance was obtained.

Samples such as skin scrapings, nail clippings, subungual scrapings and hair were collected under aseptic conditions after obtaining informed consent from the patients.

\section{Specimen collection (Larone, 2011)}

Scrapings of skin were taken from the active, peripheral edge of the lesion with a scalpel or the end of microscope slide, after it had been cleansed with $70 \%$ alcohol. Hair was plucked out from the root using sterile forceps. Brushings were taken from the area of scaly scalp. Infected nails were cleansed with an alcohol wipe and then scraped deeply enough (subungual scrapings) to obtain recently invaded nail tissue, using blunt end of the scalpel. The initial scrapings were discarded as they are usually contaminated. The samples 
so collected were transported in a sterile container or a black paper envelope to Microbiology laboratory for further processing.

Specimen processing (Larone, 2011)

The samples received in the Microbiology laboratory were processed as follows:

\section{Microscopy/ Potassium hydroxide (KOH) wet mount preparation}

Portion of sample is placed on a labelled slide to which few drops of $10 \% \mathrm{KOH}$ (for skin \&hair samples) solution is added. Cover slip is placed over it and the slide is gently heated over flame without boiling. The slide is then carefully examined microscopically to detect presence of fungal elements. The nail samples were submerged in $20 \% \mathrm{KOH}$ (Flores JM et al., 2009) overnight for complete softening and clearing, in order to afford good visibility.

\section{Culture}

Media used for fungal culture were Sabouraud's Dextrose Agar (SDA) with antibiotics and cycloheximide (for dermatophytes) and plain SDA without cycloheximide (for candida and nondermatophyte). Samples were inoculated on both the media, incubated at $30^{\circ} \mathrm{Cand}$ examined daily for growth.

\section{Confirmation of isolates}

The growth of moulds was confirmed by

Colony characteristics

Tease Mount with Lactophenol Cotton Blue (LPCB) to detect the morphology of fungus

Slide culture technique

The growth of yeasts was confirmed by

Colony characteristics

Gram stain of the colony
Germ tube test

Chrom agar

Tease mount (Larone, 2011)

Place a drop of LPCB on a clean glass slide. With a sterile bent dissecting needle or sterile loop, remove a small portion of the colony from the agar surface and place it in the drop of LPCB. With two dissecting needles, gently tease apart the mycelial mass of the colony on the slide, cover with a coverslip, and observe under the microscope with low power (10X) and high-dry (40X) objective lenses.

\section{Slide culture technique (Larone, 2011)}

It is done to study the undisturbed morphology of fungi which helps to identify the fungal species. A microscopic slide is placed on a bent glass rod at the bottom of the petri dish with a filter paper. A piece of $1 \mathrm{~cm}$ block of SDA is put on the slide. The fungal growth obtained is inoculated at four sides of the agar block and covered with a sterile cover slip. Few drops of water are added on the filter paper to avoid drying of the agar. The lid of the petri dish is closed, the preparation is left at room temperature. When the growth appears approximately after 7-14 days (dermatophytes) or 3-4 days (nondermatophytic molds) a drop of lactophenol cotton blue (LCB) is placed on the slide and the cover slip from the block is placed on it. This slide is examined microscopically for the structural arrangement of the fungi.

\section{Gram stain (Allen et al., 2005)}

Smear from the yeast-like colonies were prepared on a clean glass slide and subjected to Gram stain (according to standard procedure). They were then observed under microscope for the presence of Gram positive budding yeast-like cells. 


\section{Germ tube test (Larone, 2011)}

The culture showing yeast like dry and pasty colonies are treated with mammalian (foetal, bovine, sheep or normal human) serum and incubated at $37^{\circ} \mathrm{C}$ for 2 to 4hours. A drop of this suspension is placed on the slide, covered with a cover slip and examined microscopically for germ tubes which are seen as long tube like projections extending from the yeast cells.

\section{Chrom agar (Chander, 2009)}

It is selective and differential chromogenic medium used for identification of various candida species. It is based on direct detection of specific enzymatic activities by adding multiple chemical dyes i.e substrates of fluorochrome to media. Yeast like colonies obtained from SDA are inoculated on this agar, incubated at room temperature $\left(30^{\circ} \mathrm{C}\right)$ for 48-72 hours and looked for following colours of colonies:-

C.albicans -Light green

C.dubliniensis - Dark green

C.glabrata - Pink to Purple

C.krusei - Pink

C.parapsilosis - Cream to Pale pink

C.tropicalis - Blue with Pink halo

All the materials required for culture were obtained from HiMedia Laboratories Pvt Ltd, Mumbai, India.

\section{Statistical analysis}

The results were expressed as percentages for the analysis of various data. Microsoft excel was used for the interpretation of these results.

\section{Results and Discussion}

A total of 394 patients attended the dermatology OPD during the study period.
Out of these, 48 clinically suspected cases of superficial fungal infections were studied. Out of the 48 clinical cases $62.5 \%$ (30) were males and $37.5 \%$ (18) were females with a male to female ratio of 1.67:1. Prevalence of superficial fungal infections in our study was $10.4 \%$ (41/394). The most common age group affected was between 31-45 years (33.33\%), followed by $16-30$ years $(27.08 \%)$ (Table 1). Out of the 48 clinical samples, $39.58 \%$ (19/48) were skin scrapings, $31.25 \%$ (15/48) were hair samples and $29.16 \%(14 / 48)$ were nail clippings [Chart 1]. Out of the 48 cases, $85.41 \%$ (41) were culture positive, of which $77.08 \%$ (37) were both $\mathrm{KOH}$ and culture positive, $8.33 \%$ (4) were $\mathrm{KOH}$ negative and culture positive. $14.58 \%$ (7) were both $\mathrm{KOH}$ and culture negative. There were no cases where $\mathrm{KOH}$ was positive and culture negative (Table 2).

Out of the 41 positive cultures obtained, $70.73 \%$ (29) were dermatophytes and $29.26 \%$ (12) were non-dermatophytes. Among the dermatophytes, T.rubrum $48.27 \%$ (14/29) was the most common isolate and among nondermatophytes candida species 50\% (6/12) were the commonest isolates.

Overall, T.rubrum $34.14 \%$ (14/41) was the commonest isolate, followed by T.mentagrophytes $19.51 \%$ (8/41), C.albicans $12.20 \%$ (5/41) and M.gypseum 9.76\% (4/41). Other isolates were T.verrucosum, Curvularia, A.fumigatus $(4.89 \%$ each, i.e 2 each) and T.tonsurans, C.parapsilosis, Bipolaris and Alternaria spp $(22.43 \%$ each i.e. 1 each) [Chart 2].

There were no cases of mixed infections, Malassezia infections and infections due to Epidermophyton spp in this study.

Different types of Superficial mycoses cases which were studied are described in Table 3. It was observed that Onychomycoses (29.17\%), 
Tinea corporis (25\%) and Tinea capitis $(20.83 \%)$ were the commonest types of Superficial mycoses in our study (Fig. 1 and 2).

Significance of the results related to research work

Superficial mycoses form a large group of patients attending the Dermatology OPD of our tertiary care hospital. Apart from the clinical symptoms superficial fungal infections can cause debilitating effects on a person's quality of life. Although rarely life threatening they may in some circumstances spread to other individuals or become invasive. Most superficial fungal infections are easily diagnosed and readily amenable to treatment (Abida Malik et al., 2014).

Prevalence of superficial fungal infections in our study was $10.4 \%$. This was in concordance with other studies which showed similar prevalence rate of $12.61 \%$ (Flores et al., 2009) and 9.16\% (Eftekharjo et al., 2015).

In the present study, males were more affected than female with a male to female ratio of 1.67:1. Other studies done in India, showed similar observation with male to female ratios of 1.79:1, 4.26:1, 1.8:1 and 1.63:1 respectively (Grover et al., 2003; Kannan et al., 2006; Nawal et al., 2012 and Surendran et al., 2014). But a study done by Dulla et al., 2015, showed that females were more affected than males with female to male ratio of 1.1:1. Increased incidence in males can be attributed to their greater outdoor exposure and physical activity.

Persons of all ages were susceptible but maximum cases of fungal infection occurred between the age group of 31-45 years (33.33\%) followed by $16-30$ years $(27.08 \%)$. This was in concordance with study done by Dulla et al., (2015), which showed a higher prevalence in the age group 31-40 (26.4\%) years.
The culture positivity rate was $85.41 \%$, which was in concordance with study done in Iran (Eftekharjo et al., 2015), which showed 84.1\% culture positivity. But other studies (Surendran et al., 2014; Dulla et al., 2015 and Prasad et al., 2013) done in India showed lesser culture positivity rate of $39 \%, 57.6 \%$ and $69.51 \%$ respectively.

The $\mathrm{KOH}$ positivity rate was $77.08 \%$, and comparable with studies done in various parts of India 70.4\% (Dulla et al., 2015) and 75.57\% (Prasad et al., 2013). But lesser when compared to the study done by Surendran et al., (2014) which showed a positivity of $96 \%$.

In our study, $8.33 \%$ were $\mathrm{KOH}$ negative and culture positive. Culture was found to be superior to $\mathrm{KOH}$ wet mount. Though $\mathrm{KOH}$ wet mount is rapid, but at times gives false negative results which misleads the clinician. Hence all the $\mathrm{KOH}$ negative samples need to be cultured to confirm the diagnosis and to identify the undetected cases. The drawback of fungal culture is that it is time consuming.

The different clinical types of superficial mycoses and the various fungi isolated in this study are compared with other Indian studies in table 3, 4, 5, 6 and 7. Onychomycoses (29.17\%) was the most common type of superficial mycoses in our study whereas Tinea corporis was the most common type of clinical presentation in other studies (30.19\%, Bhatia et al., and $44.3 \%$, Surendran et al.,). Dermatophytes, especially T.rubrum was the commonest isolate in most of the studies (Dulla et al., 2015; Prasad et al., 2013 and Abida Malik et al., 2014) except for the study done by Bhatia et al., where $T$. mentagrophytes $(64.9 \%)$ was the most common dermatophyte isolated. Among the non-dermatophytes, Candida species (14.63\%) were the most common isolate in our study which was similar to study done by Surendran et al., (2014) (67.5\%). 
Table.1 Age distribution of suspected clinical cases

\begin{tabular}{|l|l|l|}
\hline Age group of patients (in years) & Number of patients & Percentage $(\boldsymbol{\%}) \mathbf{n = 4 8}$ \\
\hline $\mathbf{5}-\mathbf{1 5}$ & 6 & 12.5 \\
\hline $\mathbf{1 6}-\mathbf{3 0}$ & 13 & 27.08 \\
\hline $\mathbf{3 1}-\mathbf{4 5}$ & 16 & 33.34 \\
\hline $\mathbf{4 6}-\mathbf{6 0}$ & 8 & 16.67 \\
\hline $\mathbf{>} \mathbf{6 0}$ & 5 & 10.41 \\
\hline Total & 48 & 100 \\
\hline
\end{tabular}

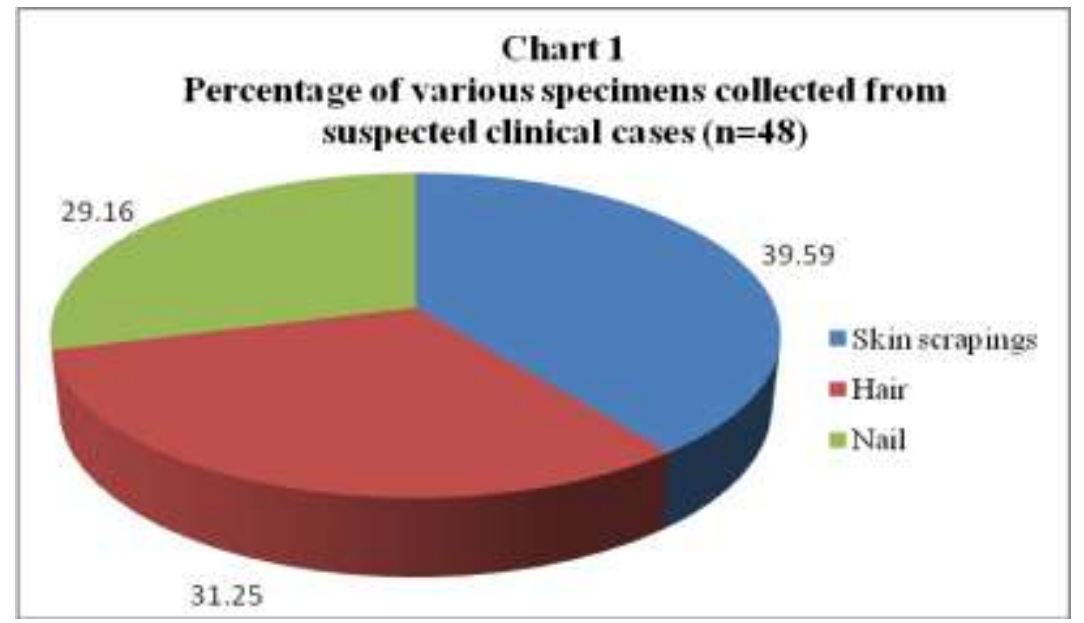

Table.2 Frequency of positive and negative results after specimen examinations (Direct microscopy Vs Culture

\begin{tabular}{|l|l|l|l|}
\hline Diagnostic test & KOH positive & KOH negative & Total (n=48) \\
\hline Fungal culture positive & $37(77.08 \%)$ & $4(8.33 \%)$ & $41(85.41 \%)$ \\
\hline Fungal culture negative & $0(0)$ & $7(14.59 \%)$ & $7(14.59 \%)$ \\
\hline Total & $37(77.08 \%)$ & $11(22.92 \%)$ & $48(100 \%)$ \\
\hline
\end{tabular}

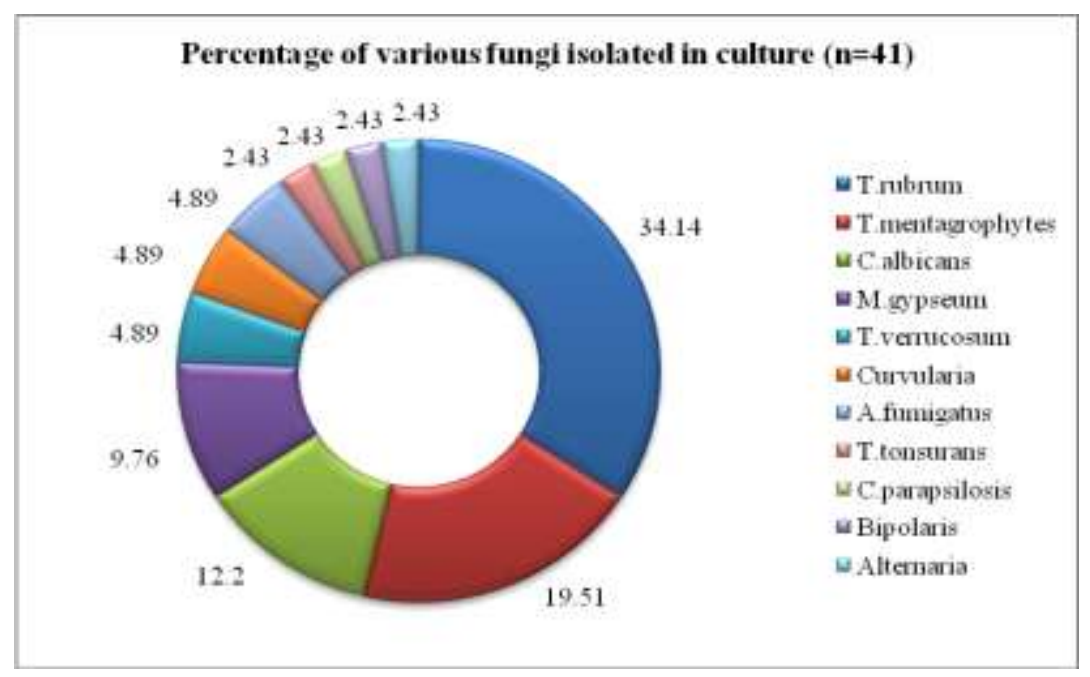


Table.3 different types of superficial mycoses cases isolated in our study

\begin{tabular}{|l|c|c|c|c|}
\hline $\begin{array}{l}\text { Provisional } \\
\text { clinical diagnosis }\end{array}$ & $\begin{array}{c}\text { Number of } \\
\text { cases }\end{array}$ & $\begin{array}{c}\text { Percentage of cases } \\
(\mathbf{n = 4 8})\end{array}$ & $\begin{array}{c}\text { KOH mount } \\
\text { positive }\end{array}$ & $\begin{array}{c}\text { Fungal Culture } \\
\text { positive }\end{array}$ \\
\hline Tinea corporis & 12 & $25 \%$ & 10 & 12 \\
\hline Tinea capitis & 10 & $20.83 \%$ & 6 & 6 \\
\hline Tinea barbae & 5 & $10.42 \%$ & 3 & 4 \\
\hline Tinea cruris & 5 & $10.42 \%$ & 4 & 5 \\
\hline Tinea pedis & 1 & $2.08 \%$ & 1 & 1 \\
\hline Tinea manuum & 1 & $2.08 \%$ & 1 & 1 \\
\hline Onychomycosis & 6 & $29.17 \%$ & 12 & 12 \\
\hline Total & 48 & 100 & 37 & 41 \\
\hline
\end{tabular}

Table.4 Comparison of clinical cases isolated with other studies

\begin{tabular}{|l|c|c|c|}
\hline $\begin{array}{l}\text { Provisionalclinical } \\
\text { diagnosis }\end{array}$ & $\begin{array}{c}\text { Present } \\
\text { study }\end{array}$ & $\begin{array}{c}\text { Karnataka (Surendran } \\
\text { et al) }\end{array}$ & $\begin{array}{c}\text { Himachal Pradesh (Bhatia } \\
\text { et al) }\end{array}$ \\
\hline Tinea corporis & $25 \%$ & $44.3 \%$ & $30.19 \%$ \\
\hline Tinea capitis & $20.83 \%$ & $0 \%$ & $3.96 \%$ \\
\hline Tinea barbae & $10.42 \%$ & $2.1 \%$ & $0.49 \%$ \\
\hline Tinea cruris & $10.42 \%$ & $38.2 \%$ & $17.32 \%$ \\
\hline Tinea pedis & $2.08 \%$ & $2.7 \%$ & $16.83 \%$ \\
\hline Tinea manuum & $2.08 \%$ & $3.3 \%$ & $3.96 \%$ \\
\hline Onychomycosis & $29.17 \%$ & $8.1 \%$ & $23.26 \%$ \\
\hline
\end{tabular}

Table.5 Fungi isolated from superficial fungal infections: A comparison with different studies conducted in India

\begin{tabular}{|l|l|l|l|l|}
\hline & $\begin{array}{l}\text { Present } \\
\text { study }\end{array}$ & $\begin{array}{l}\text { Vijayawada } \\
(\text { Dulla } \text { et al) }\end{array}$ & $\begin{array}{l}\text { Aligarh study } \\
\text { (Abida Malik } \text { et al) }\end{array}$ & $\begin{array}{l}\text { Cuttack study } \\
(\text { Prasad } \text { et al) }\end{array}$ \\
\hline Dermatophytes & $70.37 \%$ & $68.7 \%$ & $72 \%$ & $52.53 \%$ \\
\hline Non-dermatophytes & $29.26 \%$ & $31.3 \%$ & $18.8 \%$ & $4.38 \%$ \\
\hline
\end{tabular}

Table.6 Distribution of Dermatophytic isolates in comparison with other studies

\begin{tabular}{|l|l|l|l|l|l|l|}
\hline & $\begin{array}{l}\text { Present } \\
\text { study }\end{array}$ & Dulla et al & Bhatia et al & Prasad et al & Surendran et al & Abida Malik et al \\
\hline T.rubrum & $34.14 \%$ & $36.4 \%$ & $35.1 \%$ & $50.92 \%$ & $67.5 \%$ & $58.5 \%$ \\
\hline T.mentagrophytes & $19.51 \%$ & $27.3 \%$ & $64.9 \%$ & $27.77 \%$ & $20 \%$ & $21.1 \%$ \\
\hline $\begin{array}{l}\text { Microsporum } \\
\text { gypseum }\end{array}$ & $9.5 \%$ & $3.6 \%$ & $1.35 \%$ & Nil & Nil & $4.1 \%$ \\
\hline T.verrucosum & $4.88 \%$ & $3.6 \%$ & Nil & Nil & Nil & Nil \\
\hline T.tonsurans & $2.43 \%$ & $7.3 \%$ & Nil & Nil & Nil & Nil \\
\hline
\end{tabular}


Table.7 Distribution of Non-dermatophytic fungal isolates in comparison with other studies

\begin{tabular}{|l|l|l|l|l|}
\hline & $\begin{array}{l}\text { Present } \\
\text { study }\end{array}$ & $\begin{array}{l}\text { Vijayawada } \\
\text { (Dulla.et al) }\end{array}$ & $\begin{array}{l}\text { Karnataka } \\
\text { (Surendran et al) }\end{array}$ & $\begin{array}{l}\text { Aligarh (Abida Malik } \\
\text { et al) }\end{array}$ \\
\hline Candida species & $14.63 \%$ & $12 \%$ & $67.5 \%$ & $3.5 \%$ \\
\hline A.fumigatus & $4.88 \%$ & $4 \%$ & $20 \%$ & $15.6 \%$ \\
\hline Curvalaria & $4.88 \%$ & $12 \%$ & Nil & Nil \\
\hline Alternaria & $2.43 \%$ & $20 \%$ & Nil & $6.25 \%$ \\
\hline
\end{tabular}

Fig.1 Identification of yeasts

\section{Culture on SDA}

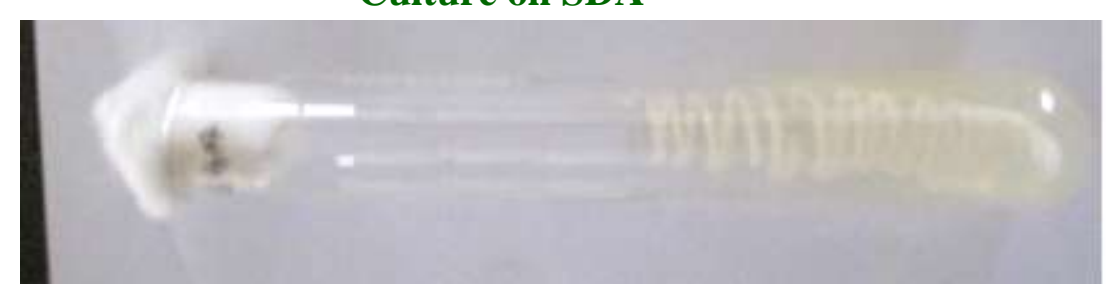

Gram stain of the colony

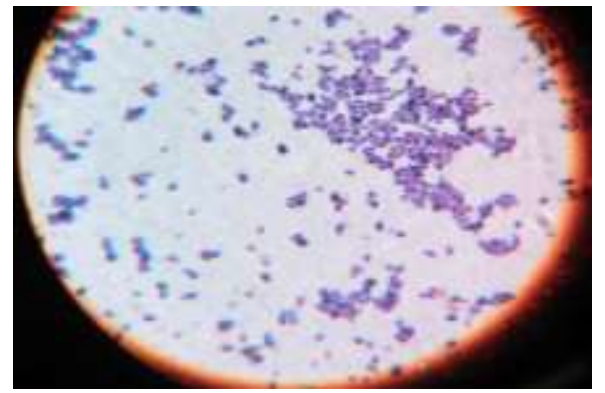

Germ tube test

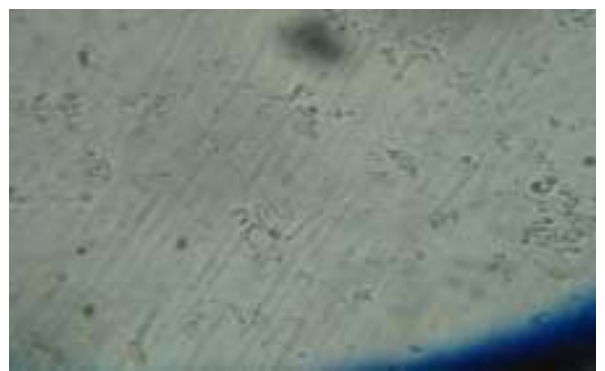

Chrom agar Candida

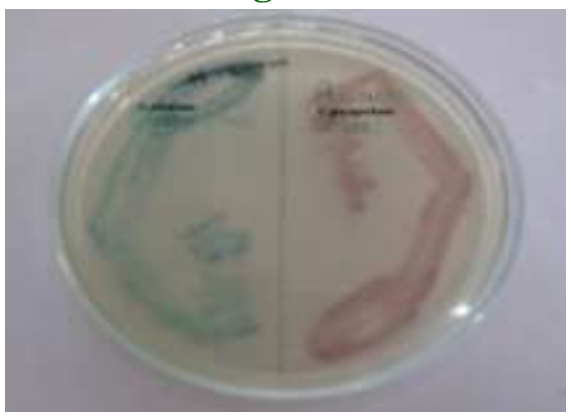


Fig.2 Identification of moulds

\section{Ectothrix}

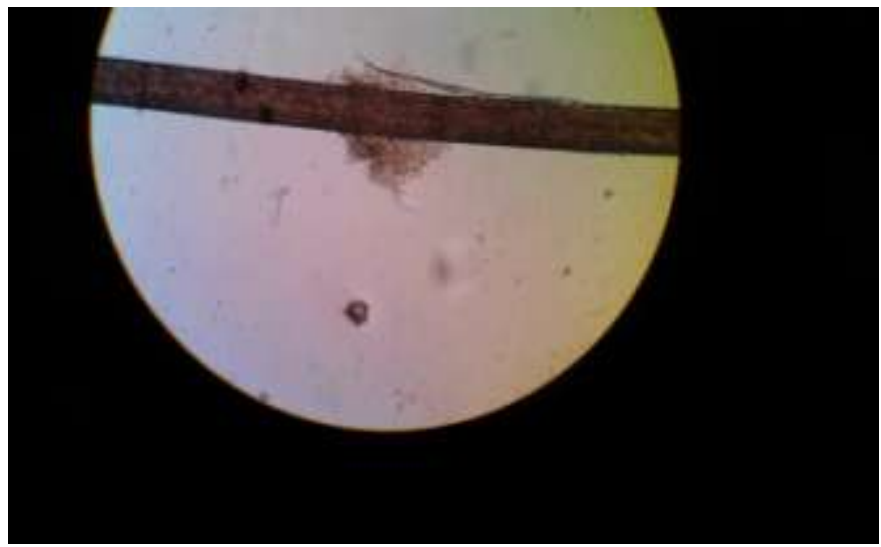

\section{T.rubrum culture}
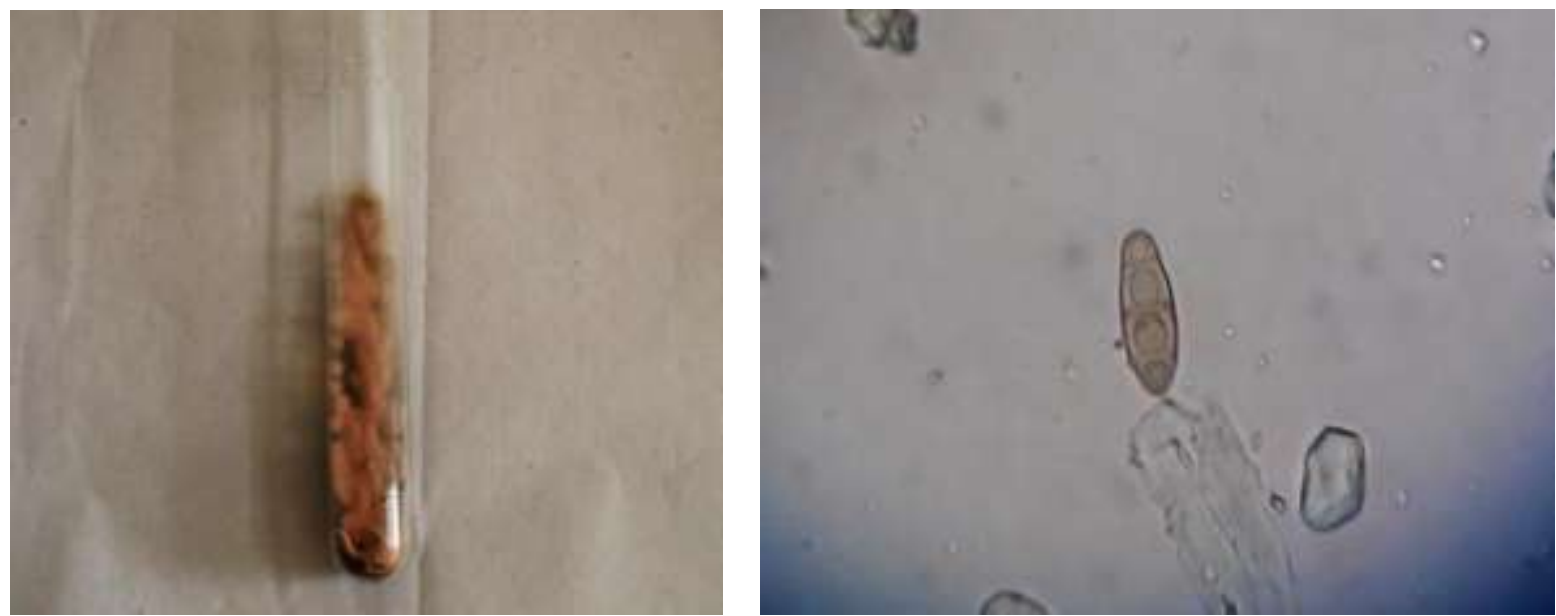

T. rubrum and T. verrucosum respectively (LPCB Mount after slide culture)
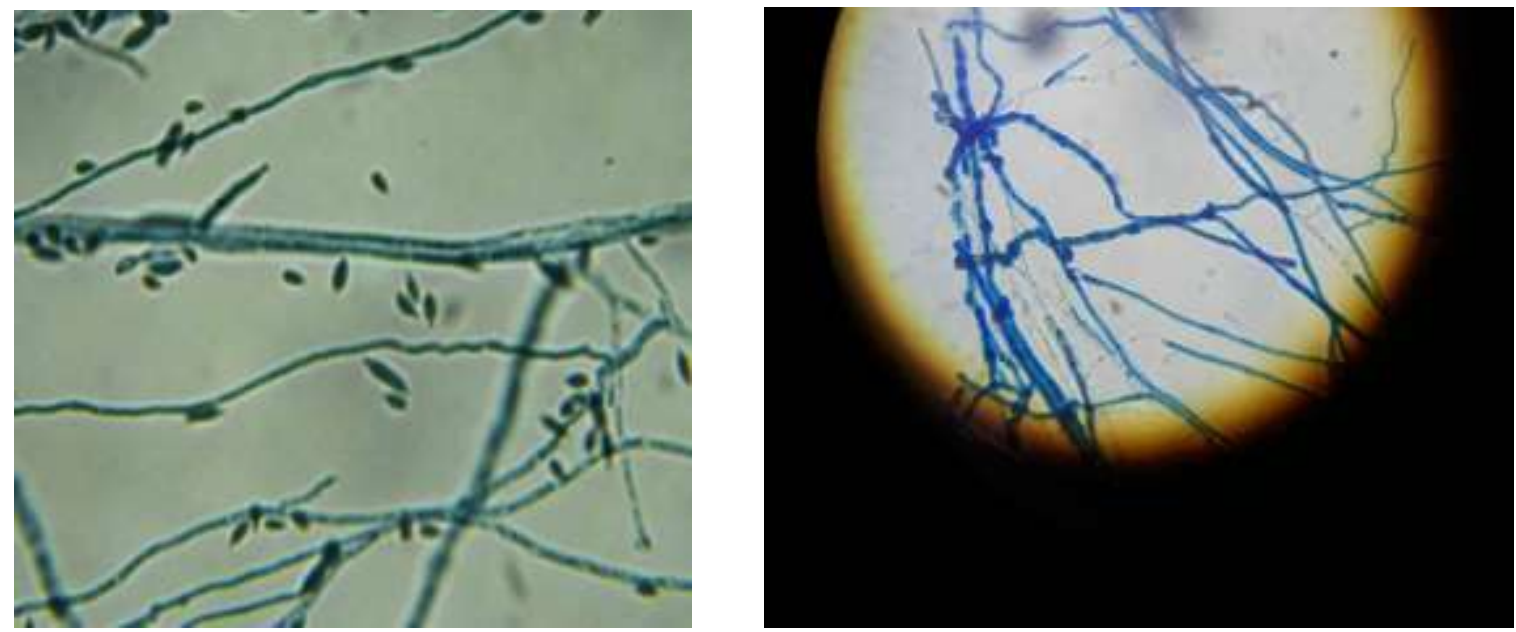
However, two studies (Dulla et al., 2015 and Abida Malik et al., 2014) done in Vijayawada and Aligarh showed that Alternaria (20\%) and A. fumigatus (15.6\%) were the most common non-dermatophyte species isolated respectively. From the above comparisons, it is clear that dermatophytes still continue to be the commonest causative agents in many parts of India. However, non-dermatophytic molds are also emerging as important causative agents and can no longer be neglected. The climatic conditions, overcrowding, unhygienic habits, occupational conditions and ignorance of common people have led to the persistence of these infections even though many of these infections are easily treatable.

In this study, Bipolaris was the rare fungal agent to be isolated and not many studies in India have reported it. This suggests that even rare fungal agents are prevalent in certain parts of our country and more studies are required from such regions in this regard.

It is concluded that along with dermatophytes, dermatomycotic fungi are also emerging as an important cause of superficial mycoses.

Though culture was found to be more sensitive than $\mathrm{KOH}$ mount in our study, both direct microscopy and cultures are important tools of diagnosis for the superficial fungal infections.

Good hygiene, sanitation and proper hand washes are effective methods for prevention of such infections.

\section{Acknowledgements}

We thank sincerely all the staff members of department of Dermatology for their timely support and guidance while conducting this study.

\section{References}

Abida Malik, Nazish Fatima, Parvez Anwar Khan (2014) A Clinico-Mycological Study of Superficial Mycoses from a Tertiary Care Hospital of a North Indian Town. Virol-mycol 3: 135. doi:10.4172/2161-0517.1000135.

Allen SD, Janda WM, Koneman EW, Schreckenberger PC, Winn WC. Koneman's Color Atlas and Textbook of Diagnostic Microbiology. 6th ed. Philadelphia: Lippincott; 2005.p.14431535.

Bhatia and Sharma: Epidemiological studies on Dermatophytosis in human patients in Himachal Pradesh, India. SpringerPlus 2014 3:134.

BrownGD, DenningDW, GowNAR., LevitzSM, NeteaMG, WhiteTC, Hidden killers: Human fungal infections. Sci. Transl. Med. (2012)4,165rv13.

Chander J. Text book of medical mycology. $3^{\text {rd }}$ ed. Appendix A - Fungal culture media. Mehta publishers, New Delhi; January 2009.p. 512.

Dulla S, Kumari PS and Kumari RL. Prevalence of Nondermatophytes in Clinically Diagnosed Tineasis. Int.J.Curr.Microbiol.App.Sci(2015) 4(7): 541-549.

Eftekharjo Y, Balal A, Taghavi M, Rahimi Z $S$ and Nikaein D. Epidemiology and prevalence of superficial fungal infections among dormitory students in Tehran, Iran.

Flores J.M, Castillo V.B, Franco F.C, Huata A.B- Superficial fungal infections: clinical and epidemiological study in adolescents from marginal districts of Lima and Callao, Peru. J Infect DevCtries2009; 3(4): 313-317.

Grover WCS, Roy CP. Clinico-mycological profile of superficial mycosis in a 
hospital in north east India. MJAFI 2003; 59:2:114-116.

Journal of Mycology Research, March 2015; 2( 1): 49-54.

Kannan P, Janaki C, Selvi G S. Prevalence of dermatophytes and other fungal agents isolated from clinical samples. Indian J Med Microbiol 2006; 24: 212-215.

Langan C, Westbrook P and Coulthwaite L. Detecting dermatophyte infections in hair, skin and nail samples. The Biomedical scientist. Nov 2010;803804.

Larone DH. Medically important fungi. $4^{\text {th }}$ ed. ASM Press, Washington DC. Part III Laboratory technique; p 296, 298, 300, 304, 307.

Nawal P, Patel S, Patel M, Soni S, Khandelwal N. A Study of Superficial Mycosis in Tertiary Care Hospital. NJIRM 2012; 3(1): 95-99.

Patel P, Mulla S, Patel D, Shrimali G. A study of superficial mycosis in South
Gujarat region. National Journal of Community Medicine 2010; 1(2):8588.

Peerapur BV, Inamdar AC, Pushpa PV, Srikant B. Clinicomycological study of Dermatophytosis in Bijapur. Ind $J$ Med Microbiol 2004;22:273-4.

Petmy LJ, Lando AJ, Kaptue L, Tchinda V, Folefack M. Superficial mycoses and HIV infection in Yaounde. J Eur Acad Deramtol. Venereol., 2004; 8: 3014.

Prasad N, Mahapatra A and Chayani N. Changing Trends in the Fungal Isolates from Clinical Specimens of Suspected Superficial Mycosis. Indian Medical Gazette -February 2013; Pp. 60-62.

Surendran KAK, Bhat RM, Boloor R, Nandakishore B and Sukumar D. A Clinical and Mycological Study of Dermatophytic Infections. Indian $J$ Dermatol. 2014 May-June; 59(3): 262-267.

\section{How to cite this article:}

Vasudha, C.L., B. Anuradha and Meer Muzaffar Ali Faizan. 2019. A Study on Prevalence and Clinico-Mycological Profile of Superficial Fungal Infections in a Tertiary Care Hospital. Int.J.Curr.Microbiol.App.Sci. 8(01): 2553-2563. doi: https://doi.org/10.20546/ijcmas.2019.801.268 